\title{
Suspended solids transport simulation for Siakap North Petai oil and gas platform: Cost-effective and environmentally sustainable offshore disposal of wastes
}

\author{
Su Yean Teh ${ }^{1, *}$, Hock Lye Koh ${ }^{2}$ \\ 1School of Mathematical Sciences, Universiti Sains Malaysia, 11800 USM, Pulau Pinang, Malaysia \\ 2 Jeffrey Sachs Center on Sustainable Development (JSC), Sunway University, Jalan Universiti, Bandar Sunway, 47500 Selangor, \\ Malaysia
}

\section{A R T I C L E IN F O}

\section{Article history:}

Received 11 February 2017

Received in revised form

23 September 2017

Accepted 4 October 2017

\section{Keywords:}

Suspended solids disposal

Environmental sustainability

Oil and gas platform

\begin{abstract}
A B S T R A C T
Offshore oil and gas exploration in deep water is more expensive compared to onshore. Strained by current low prices of crude oil, cost rationalization is essential for economic viability of oil and gas exploration offshore. Offshore exploration involves costly activities such as well drilling, well completion and testing as well as installation of flow lines and subsea facilities. Well drilling generates drill cuttings which may be disposed either onshore or offshore. Onshore disposal is not cost-effective and operationally complicated, and should be the option of last resort. More cost-effective offshore disposal of drill cuttings should therefore be utilized if it can be proven to be environmentally sustainable to the marine environment and ecosystems. This research was initiated to assess the environmental sustainability of offshore disposal of drill cuttings by means of model simulations. A critical concern in drill cuttings offshore disposal is the suspended solids (SS) created that might pose adverse impact to marine ecosystems. This paper presents the results of a simulation study by means of AQUASEA, developed by Vatnaskil Consulting Engineers, on the transport and fact of SS at an offshore oil and gas exploration platform in Siakap North Petai Field, off Sabah in the South China Sea. Simulated SS plumes subject to the dominant semi-diurnal tidal flows in the South China Sea and local eddies will be presented. Simulation results indicate that this offshore disposal of drill cuttings is environmentally sustainable at the current rates of well drilling.
\end{abstract}

(C) 2017 The Authors. Published by IASE. This is an open access article under the CC BY-NC-ND license (http://creativecommons.org/licenses/by-nc-nd/4.0/).

\section{Introduction}

Malaysia is ranked second in the world as the liquefied natural gas exporter and the second largest producer of oil and natural gas in Southeast Asia behind Indonesia. Nearly a quarter of the gross domestic product in Malaysia is generated by the energy industry, contributing significantly to the overall growth of the economy. Natural gas and petroleum are the major energy source in Malaysia, contributing $36 \%$ and $40 \%$ respectively. Malaysia is ranked 14 th in the world in terms of gas reserves, which is estimated to be exhausted in 42 years; while reserves of crude oil and condensates are estimated to last 28 years at current production

\footnotetext{
* Corresponding Author.

Email Address: syteh@usm.my (S. Y. Teh)

https://doi.org/10.21833/ijaas.2017.012.017

2313-626X/C 2017 The Authors. Published by IASE.

This is an open access article under the CC BY-NC-ND license

(http://creativecommons.org/licenses/by-nc-nd/4.0/)
}

levels (MOF, 2014). After Terengganu, Sabah shows a great potential in becoming the second largest oilproducing state in Malaysia due to recent deep water discovery and development of new offshore oil and gas fields. Currently Sabah contributes $14 \%$ of natural gas and $30 \%$ crude oil reserve for Malaysia. There are several projects that are under development around offshore Sabah deep water that can further increase Malaysia's oil production for the next few decades. It is critical to ensure that the oil and gas production in offshore fields around Sabah can be economically/environmentally sustainable, particularly during hard time characterized by extremely low crude oil prices. A significant cost component in offshore exploration is related to well drilling activities. It is therefore financially essential to ensure that drilling costs be reduced substantially in order to sustain the oil producers as well as the drillers and other associated service provides. We therefore devote this paper to demonstrate that cost-effective offshore disposal of drill cuttings is 
environmentally sustainable at the current rates of well drilling. Operated by Murphy Oil, the Siakap North Petai (Kikeh) Oil Field is currently the only deep water oil field in Malaysia. Kikeh was estimated to produce about $60000 \mathrm{bbl} / \mathrm{d}$ of oil in 2013, although it was expected to produce only 20000 $\mathrm{bbl} / \mathrm{d}$ in 2007 when it was first found. The production is expected to peak at $120,000 \mathrm{bbl} / \mathrm{d}$ upon restoration of delayed operations. The scale of this production is substantial for Malaysia.

\section{Well drilling characteristics}

To extract gas and petroleum from deep sea reserves, wells are drilled into the seabed to reach these reserves. As the drill string is turned at the surface, the teeth of the drill bit at the bottom will grind the rock into smaller cuttings that vary in sizes and characteristics. During this process, drilling fluids are pumped down the drill string to lubricate the drill bit, to maintain the required hydraulic pressure to the motor, to clean and cool the drill bit and to help in lifting the rock cuttings to the surface. As the drill fluids are carried up to the surface together with the rock fragments, the fluid mixtures will be treated on-site before being released for offshore disposal. Drilling wastes that are produced from well drilling process consists of drilling fluid (or muds) and formation of rock fragments (known as cuttings). The amount of the muds adhered to the cuttings depend on the cutting's particle size distribution. The small cuttings can remain suspended in water column as suspended solids (SS), while the larger cuttings form a pile at the toe of the seabed. Finer sediment particles that suspend in the water can interfere with respiration process in small fishes and some other marine organisms such as corals. The severity of the impact depends on the amount and duration of exposure to these SS. Water quality models are generally used to simulate the SS concentration generated by well drilling activity. In this paper, we simulate the spatial temporal distribution of SS in the top 20 meter of the water column due to drill cuttings disposal at an offshore oil and gas exploration platform in Siakap North Petai Field by means of the hydrodynamic flow and transport model AQUASEA (VCE, 1998). We will demonstrate that this mode of offshore disposal of drill cutting is environmentally sustainable at the proposed rates of drilling typically used in Malaysia.

\section{Site characteristics of Kikeh field}

Siakap North Petai (Kikeh) Field operated by Murphy Sabah Oil Co. Ltd lies in water depths of about $1200 \mathrm{~m}-1500 \mathrm{~m}$. It is located $10-15 \mathrm{~km}$ northwest of the Murphy Kikeh FPSO installation, which is situated within $120 \mathrm{~km}$ radius northwest of Labuan Island, offshore Sabah, Malaysia. Fig. 1 shows the location of Kikeh Field in the South China Sea (SCS). Fig. 2a depicts predominant surface currents in the SCS during January (Northeast Monsoon), sourced from Admiralty Charts and Publications.
Currents enter the SCS at the northern entrance and exit at the southern entrance. The predominant currents along the Sabah coast flow towards the northeast. Eddy currents in the SCS vary in scales from $100 \mathrm{~km}$ to tens of $\mathrm{km}$, providing good dispersions of suspended substances within the region. Fig. $2 \mathrm{~b}$ demonstrates predominant surface currents in the SCS during July (Southwest Monsoon). Currents enter the SCS at the southern entrance and exit at the northern entrance. The predominant currents along the Sabah coast flow towards the northeast also, with eddy currents providing good dispersions within the region. This predominant regional northeast current during both Monsoon seasons and internal eddies help to dilute and disperse SS quickly to low levels. These natural dilutions provide the mechanism to render the SS due to drill cuttings disposal harmless to marine organisms if the quantum released is not excessive. Fig. 3 provides monthly current roses derived on the basis of current measurements at Kebabangan for the period 1994-1999. The predominant current flow along the northeast direction is clearly seen. Fig. 4 provides the mean and maximum current speed at various depths in the study site, based upon analysis of current measurements at Kebabangan (19941999), as reported in DHI (2009). To reflect the site specific current regimes as summarized in Fig. 3, we will utilize the predominant NE currents regimes to simulate SS concentration in the top water column of $20 \mathrm{~m}$ in depth. The period of the semi-diurnal tidal current is 12.00 hours (Koh and Teh, 2011; NHC, 2011). Approximately $250 \mathrm{~m}^{3}$ of cuttings will be produced per well, equivalent to a total of $3250 \mathrm{~m}^{3}$ of cuttings for all 13 proposed wells (PEIA, 2011).

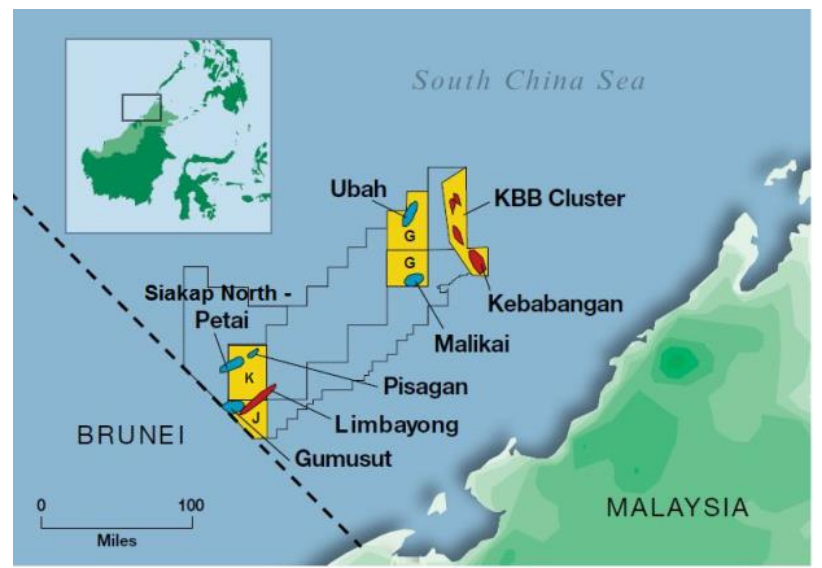

Fig. 1: Location of Siakap North Petai field

\section{Simulation results for Kikeh field}

Based upon the mean current speed as shown in Fig. 4 and tidal dispersions of around $5 \mathrm{~m}^{2} / \mathrm{s}$ (Koh et al., 1991, 1997), it can be verified that a suspended particle travel distance during a tidal cycle of 12 hours will be limited to less than $5000 \mathrm{~m}$ in the dominant direction and less than $500 \mathrm{~m}$ in the direction perpendicular to this (Koh, 2004). From computational perspective, we must ensure that all suspended particles remain well within the 
computational domain throughout the simulation. This requirement is imposed in order to avoid complicated boundary conditions that might lower computational accuracy.

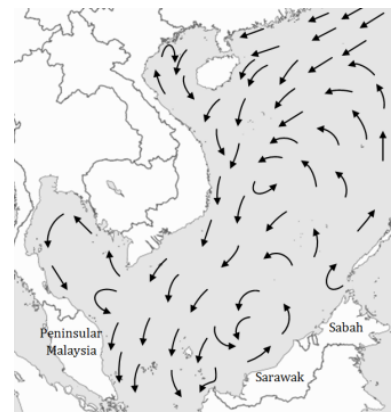

(a)

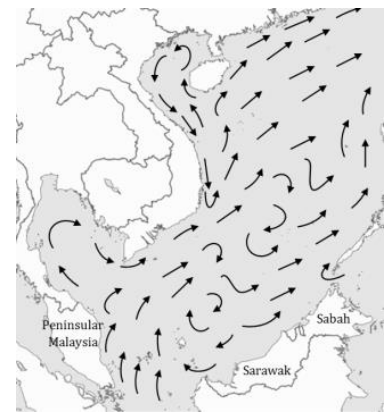

(b)
Fig. 2: Predominant surface currents in the South China Sea during January-Northeast Monsoon (a) and JulySouthwest Monsoon (b)

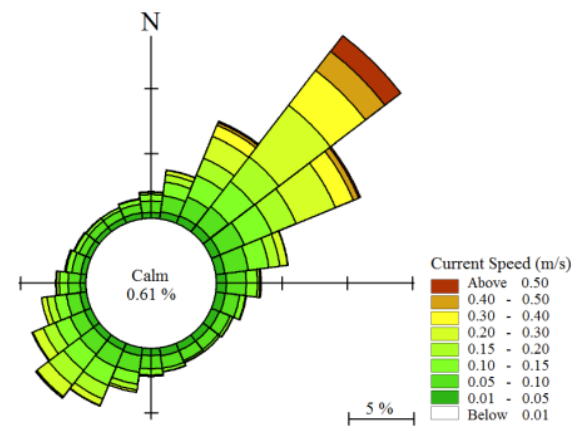

Fig. 3: All year current rose derived on the basis of current measurements at Kebabangan (1994-1999)

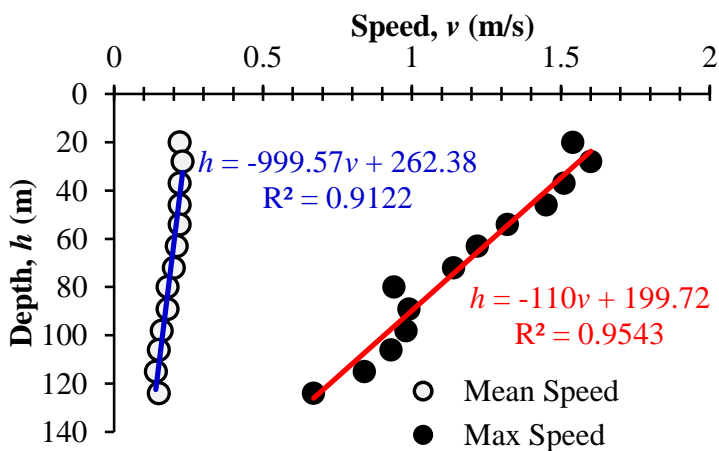

Fig. 4: Mean and maximum current speed at various depths at Kebabangan (1994-1999)

The computational domain is therefore chosen so that all SS contours are completely contained within the computational domain. Because the dominant currents flow in one direction, a simple rectangular domain is appropriate. A dimension of $10,000 \mathrm{~m}$ by $2000 \mathrm{~m}$ is used, with grid size of $\Delta \mathrm{X}=\Delta \mathrm{Y}=100 \mathrm{~m}$. $\mathrm{A}$ grid of $100 \mathrm{~m}$ is not adequate to resolve the steep SS concentration gradient anticipated at the disposal location. A simple analysis indicates that a grid size of $25 \mathrm{~m}$ is sufficient. To provide adequate resolution near the discharge point, the area surrounding the discharge point therefore further refined twice so that within the refined sub-domain, the grid size is reduced to $\Delta \mathrm{X}=\Delta \mathrm{Y}=25 \mathrm{~m}$, in the neighborhood of where SS is discharged, as shown in Fig. 5a. Further reduction of grid size beyond $25 \mathrm{~m}$ will not improve simulation accuracy. The tidal hydrodynamic regime used for the SS simulation is the mean semi-diurnal tide with a period of 12.00 hours and a mean depthaveraged tidal velocity given by $\mathrm{u}=0.2 \sin (\sigma \mathrm{t}) \mathrm{m} / \mathrm{s}$. The simulated tidal velocity is shown in Fig. $5 \mathrm{~b}$. It is noted that the SS concentrations resulting from stronger tidal currents exceeding $u=0.2 \sin (\sigma t)$ will be lower, with less adverse impact. The simulation results for this scenario are therefore omitted in this paper, due to space constraint.

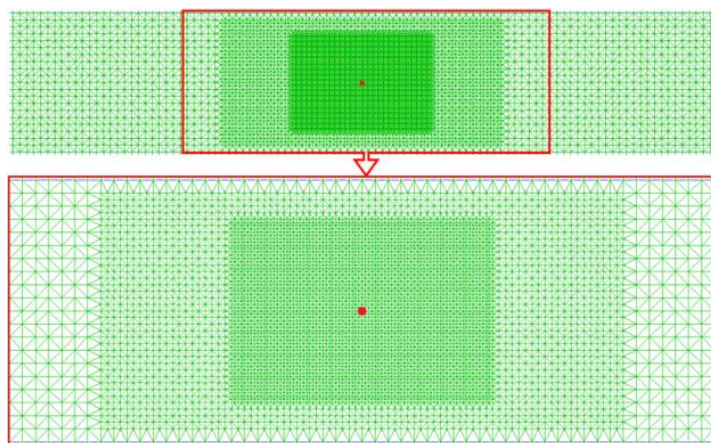

(a)

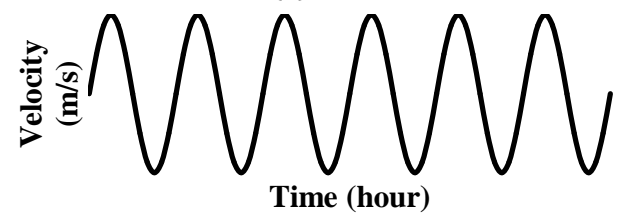

(b)

Fig. 5: Finite element mesh with twice-refined mesh with SS discharge location indicated as red dot (top) and simulated tidal velocity (bottom)

Suspended solids (SS) discharge rates (kg/s) vary over the period of the drilling operation, resulting in varying SS concentration in the water column. Higher SS discharge rates lead to higher SS concentrations in the water column. Details regarding the drilling schedules were not available for the Siakap North Petai Field. Hence, we simulate SS spatial-temporal distribution that will be resulted from the highest SS discharge rate in order to assess the worst-case scenario for potential impact of SS. The thirteen wells are expected to be drilled sequentially, one after another. Therefore, at any one time, only a total $250 \mathrm{~m}^{3}$ of drill cuttings from one well will be produced during the drilling operation. Based upon drill cuttings size distribution reported by other drilling operations (Bell et al., 1998; Rye et al., 2006), $50 \%$ of drill cuttings consist of larger particles that quickly settle onto the seabed to form seabed pile. The remaining $50 \%$ are very fine particles that suspend in the water column as suspended solids. Drilling operation for $250 \mathrm{~m}^{3}$ of cuttings can normally be completed within one day. We therefore assume that the drilling will take place uniformly over exactly one day, giving rise to an SS discharge rate of $50 \% \times 250 \mathrm{~m}^{3} \times 2.4$ tons $/ \mathrm{m}^{3} \div 1$ day $=300$ tons $/$ day $\approx 3.5 \mathrm{~kg} / \mathrm{s}$. An average settling velocity of $0.0012 \mathrm{~m} / \mathrm{s}$ is adopted for fine particles with mean diameter $0.1 \mathrm{~mm}$ (Tedford et al., 2003). The surface dispersion coefficients for the along-flow and cross-flow directions in the SCS used in the 
simulations are respectively $E_{x}=10.0 \mathrm{~m}^{2} / \mathrm{s}$ and $E_{\mathrm{y}}=$ $5.0 \mathrm{~m}^{2} / \mathrm{s}$ (Koh et al., 1991, 1997). These values of dispersions are appropriate for the SCS, with strong eddy dispersions. SS is discharged from hours 24 to 48 for duration of exactly one day. Subsequently the SS discharge is discontinued from hour 48 onwards, as shown in Fig. 6a. This choice of SS discharge rate is a typical drilling schedule in Malaysia. The highest SS concentration occurs at the discharge point, peaking momentarily at the value of about $15 \mathrm{mg} / \mathrm{l}$ during slack tide (Fig. 6b). Note that SS concentration quickly drops to $0 \mathrm{mg} / \mathrm{l}, 24$ hours after the termination of SS release at hour 48. Figs. 7 and 8 respectively show simulated $\mathrm{SS}$ plumes and tidal currents at three selected distinct tidal phases: during (a) flood tide, (b) slack tide and (c) ebb tide. It is obvious that the SS plumes follow the current flow direction, with more pronounced spread in the direction of current flow during flood and ebb tide. During slack tide that occurs when the currents are in the process of changing direction, the SS plumes are more confided to a small area, resulting in higher concentrations. Fig. 9 shows the SS concentration (mg/L) spatial plots along the flow axis at intervals of 3 hours, starting at hour 24 (the start of SS release) and ending at hour 51 (3 hours after the termination of SS release) covering the entire duration of 24 hours of uniform cuttings discharge. Maximum SS concentration of about $15 \mathrm{mg} / \mathrm{L}$ occurs at the well site, during slack tides. SS concentrations decrease quickly to less than $1 \mathrm{mg} / \mathrm{L}$ at one $\mathrm{km}$ away.

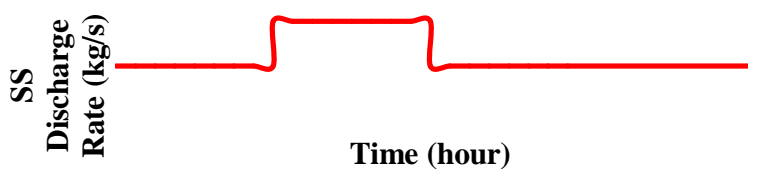

(a)

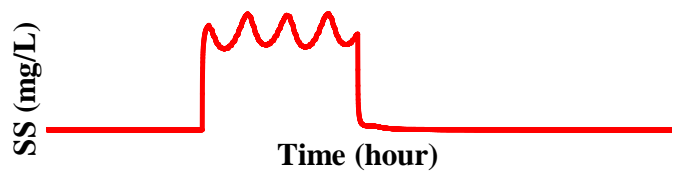

(b)

Fig. 6: SS discharge rate for 24-hour period (top) and SS concentration at discharge point (5 km, $1 \mathrm{~km}$ ) (bottom)
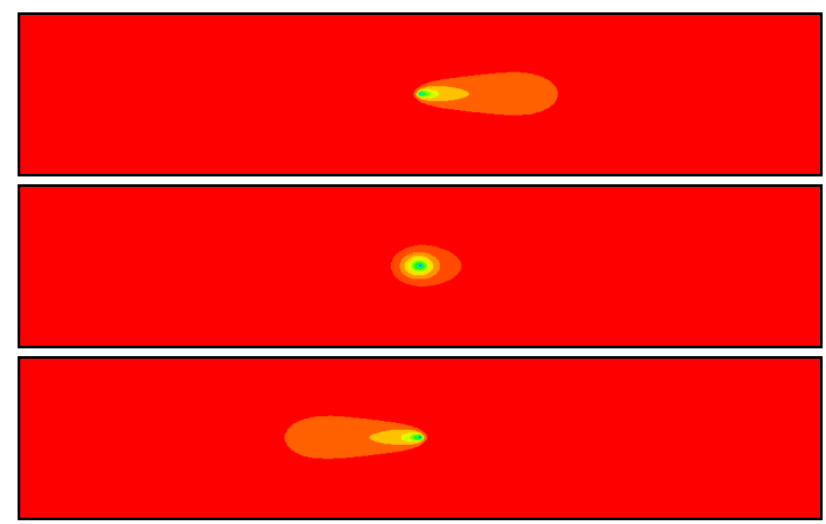

Fig. 7: Simulated SS plumes at 3 tidal intervals: during flood tide (top), turn of tide (middle) and ebb tide (bottom)

\section{Tolerance of marine animals to SS}

We now present research findings on coral resilience to SS to arrive at the conclusion in the next section. Being able to swim away from high SS, fish are less sensitive to SS compared to sessile corals. An abundance of research literature on coral tolerance to SS is readily available.

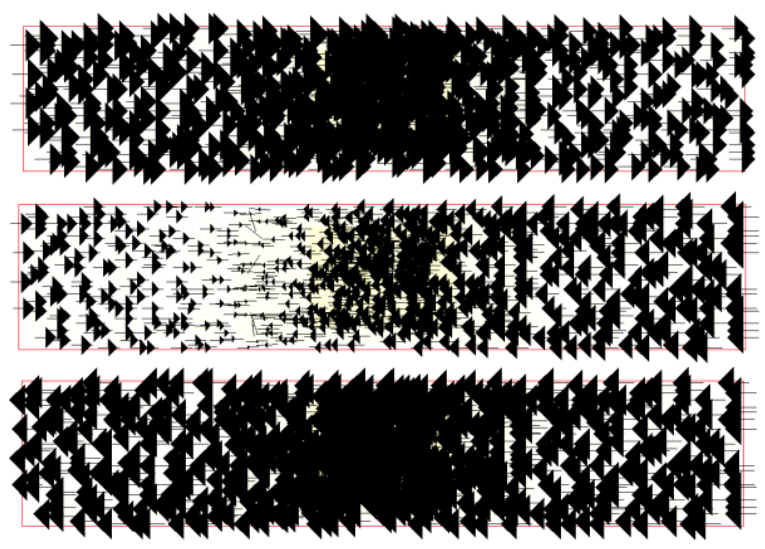

Fig. 8: Simulated tidal currents at 3 tidal intervals: during flood tide (top), turn of tide (middle) and ebb tide (bottom)

Hence, we focus our discussion on coral sensitivity to SS to assess the potential impacts of SS on marine organisms. Many studies conducted to understand corals tolerance to SS have demonstrated that some corals can indeed survive well for extended period in turbid environments laden with SS of the order of tens of $\mathrm{mg} / \mathrm{L}$ of SS (Larcombe and Woolfe, 1999; Petry and Larcombe, 2003; Perry, 2005; Perry and Smithers, 2010). These and other studies have demonstrated the occurrence of coral reefs, often with high live coral covers, in areas of high and fluctuating SS, turbidity and sedimentation, for example in the inner shelf of the Great Barrier Reef (Mapstone et al., 1989). However, Rice and Hunter (1992) noted that long-term exposure to elevated levels of SS (50 to $100 \mathrm{mg} / \mathrm{l}$ ) and high levels of coral bed sedimentation (tens of $\mathrm{mg} / \mathrm{cm}^{2} /$ day) can cause reduced coral growth and reduced reef development. Nevertheless, recent studies indicate that the observed adverse impacts are often less severe than what had been previously reported. Further, recent studies from near-shore reefs in the Great Barrier Reef provide convincing evidence of spatially relevant and temporally persistent reef-building having occurred over millennial timescales (Larcombe et al., 1995), suggesting the resilience of corals to SS. Perry and Smithers (2010) observe that corals can indeed survive well in turbid environment with high SS (tens of $\mathrm{mg} / \mathrm{L}$ ) and high sedimentation (tens of $\mathrm{mg} / \mathrm{cm}^{2} /$ day) in Singapore coastal waters. The reason for the observed resilient growth rate despite high SS and high sedimentation could be due to flushing by tidal currents that can efficiently remove sediments from corals (Anthony and Larcombe, 2002; Riegl et al., 1996). This efficient removal of sediments from corals by tidal flushing is equally 
applicable to the present study sites in the SCS, which are located in areas with good tidal flushing augmented by waves and internal eddies. Corals that are naturally exposed to high and variable background conditions of SS, turbidity and sedimentation (e.g. due to tides, storms and/or monsoon, as is the case with the study sites) will have higher tolerances to short-term pulses in SS, turbidity or sedimentation caused by dredging or drilling operations (Nieuwaal, 2012). This remark certainly applies to the study sites.

(a) $\mathrm{t}=24 \mathrm{hr}$
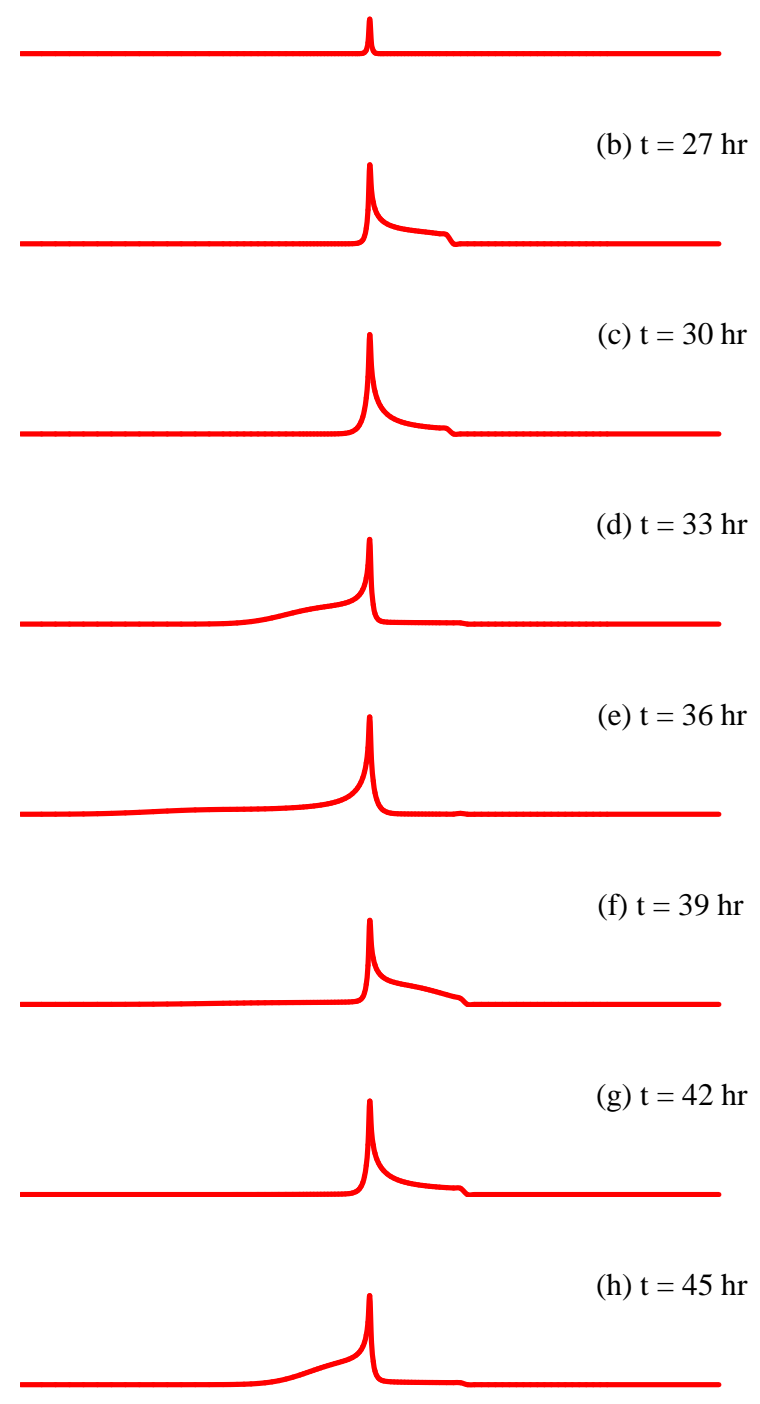

(i) $\mathrm{t}=48 \mathrm{hr}$

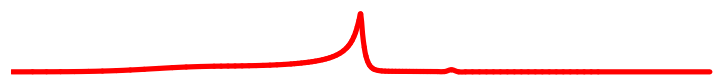

(j) $t=51 \mathrm{hr}$

Fig. 9: SS concentration profiles (concentration in $\mathrm{mg} / \mathrm{L}$ vs. distance in $\mathrm{km}$ ) at 3-hourly interval ( $\mathrm{t}=24$ to 51 hour) along the $\mathrm{x}$-axis

\section{Conclusion}

This paper presented the results of a simulation study on the transport of SS in the water column due to drill cuttings disposal at an offshore oil and gas exploration platform in Siakap North Petai Field under the mean semi-diurnal tide current velocity given by $\mathrm{u}=0.2 \sin (\sigma \mathrm{t}) \mathrm{m} / \mathrm{s}$. The SS concentrations prevalent under stronger tidal currents exceeding $\mathrm{u}=0.2 \sin (\sigma \mathrm{t})$ will be lower. The simulated depthaveraged SS concentrations achieve a short-period peak value of $15 \mathrm{mg} / \mathrm{l}$ at the discharge location during a slack tide. The SS concentration, however, drops quickly to low levels away from the release location. At $500 \mathrm{~m}$ away, the peak SS concentration drops to less than $2.0 \mathrm{mg} / \mathrm{L}$ while at $1000 \mathrm{~m}$ away, the peak SS concentration drops to less than 1.0 $\mathrm{mg} / \mathrm{L}$ along the plume centre-line. Off the plume centre-line, the SS concentrations are even lower. The SS peak concentration of $15 \mathrm{mg} / \mathrm{L}$, which occurs only at the disposal site and for a short duration, is below the stipulated suspended solid of $25 \mathrm{mg} / \mathrm{L}$ for Class 1 of the Malaysian Marine Water Quality Criteria Standard (DOE, 2015). Further, the SS plumes are limited in spatial extent and nonpersistent. The SS concentrations drop quickly to zero once the SS discharges are terminated. After stopping discharge, the SS drops to almost $0.0 \mathrm{mg} / \mathrm{l}$ in a matter of 24 hours. In view of the low concentrations and non-persistence of suspended solids, the SS will not have any adverse impact on the marine environment at the rate of well drilling of $250 \mathrm{~m}^{3}$ per day. Hence this cost-effective mode of drilling waste disposal is preferred to costly land disposal.

\section{Acknowledgment}

Financial support provided by Grant \#203/PMATHS/6730101 is gratefully acknowledged. KHL thanks Sunway University Business School for supporting this research publication.

\section{References}

Anthony KRN and Larcombe $P$ (2002). Coral reefs in turbid waters: sediment-induced stresses in corals and likely mechanisms of adaptation. In $9^{\text {th }}$ International Coral Reef Symposium, Bali, Indonesia, 1: 239-244.

Bell N, Cripps SJ, Jacobsen T, Kjeilan G, and Picken GB (1998). Review of drill cuttings piles in the North Sea. Cordah Environmental Consultants, Aberdeen, UK.

DHI (2009). Metocean criteria for Kebabangan field development, Sabah. Danish Hydraulic Institute (DHI), Kota Kinabalu, Malaysia.

DOE (2015). Malaysian marine water quality criteria and standards. Department of Environment (DOE), Ministry of Natural Resources \& Environment, Putrajaya, Malaysia.

Koh HL (2004). Pemodelan Ekosistem dan Alam Sekitar [Ecosystem and Environmental Modelling]. USM Press, Penang, Malaysia.

Koh HL and Teh SY (2011). Tsunami simulation for capacity development. In the International Multi Conference and 
Engineers and Computer Scientists (IMECS'11), Hong Kong, China, 2: 1528-1533.

Koh HL, Lim PE, and Lee HL (1997). Impact modeling of sewage discharge from Georgetown of Penang, Malaysia on coastal water quality. Environmental Monitoring and Assessment, 44(1-3): 199-209.

Koh HL, Lim PE, and Midun Z (1991). Management and control of pollution in Inner Johore Strait. Environmental Monitoring and Assessment, 19: 349-359.

Larcombe P and Woolfe KJ (1999). Increased sediment supply to the Great Barrier Reef will not increase sediment accumulation at most coral reefs. Coral Reefs, 18(2): 163-169.

Larcombe P, Ridd PV, Prytz A, and Wilson B (1995). Factors controlling suspended sediment on the inner-shelf coral reefs, Townsville, Australia. Coral Reefs, 14(3): 163-171.

Mapstone BD, Choat JH, Cumming RL, and Oxley WG (1989). The fringing reefs of Magnetic Island: Benthic biota and sedimentation- A baseline study. Great Barrier Reef Marine Park Authority, Townsville, Australia.

MOF (2014). Economic performance and prospects. Economic Report, Ministry of Finance, Putrajaya, Malaysia.

NHC (2011). Tide tables for Malaysia 2011. National Hydrographic Centre, Royal Malaysian Navy, Selangor, Malaysia.

Nieuwaal M (2012). Requirements for sediment plumes caused by dredging. M.Sc. Thesis, Delft University of Technology, Delft, Netherlands.

PEIA (2011). Preliminary environmental impact assessment (PEIA) for Proposed Siakap North - Petai deepwater development. Preliminary Environmental Impact Assessme, Chemsain, Kota Kinabalu, Malaysia.

Perry CT (2005). Structure and development of detrital reef deposits in turbid nearshore environments, Inhaca Island, Mozambique. Marine Geology, 214(1): 143-161.

Perry CT and Larcombe P (2003). Marginal and non reef-building coral environment. Coral Reefs, 22: 427-432.

Perry CT and Smithers SG (2010). Evidence for the episodic "turn on" and "turn off" of turbid-zone coral reefs during the late Holocene sea-level highstand. Geology, 38(2): 119-122.

Rice SA and Hunter CL (1992). Effects of suspended sediment and burial on scleractinian corals from West Central Florida patch reefs. Bulletin of Marine Science, 51(3): 429-442.

Riegl B, Heine C, and Branch GM (1996). Function of funnelshaped coral-growth in a high-sedimentation environment. Marine Ecology Progress Series, 145: 87-93.

Rye H, Reed M, Frost TK, and Utvik TIR (2006). Comparison of the ParTrack mud/cuttings release model with field data based on use of synthetic-based drilling fluids. Environmental Modelling and Software, 21(2): 190-203.

Tedford T, Drozdowski A and Hannah CG (2003). Suspended sediment drift and dispersion at Hibernia. Fisheries and Oceans Canada, Dartmouth, USA.

VCE (1998). AQUASEA tidal flow in estuaries and coastal areas lake circulation transport modelling. Vatnaskil Consulting Engineers, Iceland. 